\title{
DA ANÁLISE SEMÂNTICA DO DISCURSO À AÇÃO EDUCATIVA - UM MAPA DA CRISE DA SALA DE AULA
}

\author{
Neusa Salim Miranda* \\ Universidade Federal de Juiz de Fora /FAPEMIG \\ Juiz de Fora, MG, Brasil
}

Luciene Fernandes Loures ${ }^{* *}$

Colégio Tiradentes da Polícia Militar de Minas Gerais

Juiz de Fora, MG, Brasil

\begin{abstract}
Resumo: Este artigo apresenta a trajetória de um macroprojeto de natureza híbrida Linguística e Educação - que, por uma década, mediante o desenvolvimento de doze Estudos de Caso fixados no cenário escolar, vem trabalhando um modelo de análise do discurso baseado na Semântica de Frames e nos Modelos de Linguagem baseados no Uso. Valendose da narrativa de práticas de alunos e professores como metodologia de constituição de seus corpora, este estudo permitiu traçar um mapa da crise da sala de aula, com suas causas, consequências e, também, rotas de saída, o que tem conduzido não só à consolidação de um modelo de análise do discurso, como a novos caminhos para a ação educativa na sala de aula de Lingua Portuguesa e no processo de formação de professores.
\end{abstract}

Palavras-chave: Semântica de Frames. Análise do discurso. Vivência escolar.

"Quem elegeu a busca não pode recusar a travessia."

(BOSI, 2003)

1 INTRODUÇÃO

A epígrafe eleita remete ao conto Sequência (ROSA, 1962, apud BOSI, 2003), que tematiza a busca dificultosa de uma vaquinha pitanga, uma rês fujã (que viajava que nem uma criatura cristã) e de um senhor-moço que, no vão do mundo, ia, atrás dela, sem saber para onde, com vontade de desistir. E Bosi (2003, p. 45), interpretando o sentido das travessias de Guimarães Rosa, sentencia "Quem elegeu a busca não pode recusar a travessia.".

É sobre uma busca, igualmente dificultosa, de um projeto de pesquisa de natureza híbrida - Linguística e Educação, no curso de uma década, que este artigo se debruça, mostrando também a travessia que não pôde recusar-se a empreender.

A primeira questão mobilizadora deste estudo foi a percepção intuitiva e cotidiana de uma crise das práticas interacionais e linguísticas em instâncias públicas em nossa

\footnotetext{
* Professor Associado. Pós-doutora em Linguística. E-mail: neusasalim@gmail.com.

** Professora de Língua Portuguesa. Mestre em Linguística. E-mail: lucieneloures@gmail.com. 
sociedade (cerimônias religiosas, formaturas, cinemas e outros espaços de lazer e cultura). Falta de delicadezas, de generosidade; ostentação e individualismo; confusão entre o direito à fala e o dever da escuta; invasão, no domínio público, de práticas sociais do mundo privado.

Deste incômodo veio a pergunta - Qual seria o impacto de tais práticas em sala de aula? - e nasceu o primeiro projeto investigativo (MIRANDA, 2007-2015) ${ }^{1}$.

Seis estudos de caso desenvolvidos (LIMA, 2009; PINHEIRO, 2009; BERNARDO, 2011; ALVARENGA, 2012; FONTES, 2012; FONSECA, 2015) trouxeram à luz um conjunto significativo de generalizações analíticas sobre as vivências em sala de aula de ensino fundamental em redes públicas. A análise desta realidade, vista sob o ângulo de relatos de experiência de docentes e discentes minuciosamente analisados em termos de frames suscitados e reiterados na voz coletiva (Semântica de Frames e Modelos de Linguagem baseados no Uso), traçou, de modo contundente, um "mapa da crise" no espaço escolar. Deslimites das práticas interacionais e linguísticas, violência, desordem, opacidade de valores, crise de autoridade foram alguns dos indicadores deste mapa.

Nesta cena, a escola (alunos, professores e outros profissionais) nomeia com um rótulo difuso de "indisciplina" tanto a violação de regras morais (violência de todas as ordens, desrespeito, furtos...) quanto de regras convencionais (uso de uniforme, celulares, horários...) e mesmo a marcante falta de interesse dos alunos. Sem projetos para enfrentamento dessa realidade, esta instituição, via de regra, dirige suas preocupações normativas e punições para as regras convencionais (BERNARDO, 2011; ALVARENGA, 2012; FONTES, 2012).

Por outro lado, em meio às avaliações dos sujeitos, surgem também fortes indicadores de possíveis caminhos para a travessia, como o apontamento claro do papel do protagonismo jovem; a preservação do poder simbólico do professor; a afirmação da autoridade docente por meio da autoria, dos valores e do afeto; a percepção do papel de um ambiente escolar positivo. Sobressaindo-se a tudo isto, a voz coletiva dos discentes demarca a não naturalização das práticas conflituosas vividas no espaço escolar.

Neste estudo, para além dos indicadores semânticos obtidos através da análise dos discursos baseada em frames e na frequência de uso, abriu-se um diálogo interteórico com o campo da Linguística Aplicada e o das Ciências Sociais (Sociologia, Antropologia, Ética, Educação...) de modo a se elegerem os fundamentos e as categorias capazes de propiciar um exercício interpretativo destes resultados em cada estudo de caso.

Em busca de aprofundamento deste olhar, a pergunta se estreitou - Como seria o retrato desta cena em sala de aula de Lingua Portuguesa? Qual seria, pois, o papel das Letras nesta crise? -, trazendo um novo rumo investigativo para o projeto (MIRANDA, $2012)^{2}$.

É fato que, em quatro décadas de discussão e pesquisa sobre o ensino de Língua Portuguesa (doravante LP) no Brasil, uma vasta literatura sobre o tema se formou,

\footnotetext{
${ }^{1}$ Macroprojeto "Práticas de Oralidade e Cidadania", FAPEMIG, PNPD.

2 Macroprojeto Ensino de Língua Portuguesa - da Formação Docente à Sala de Aula (PPGLinguística/UFJF ; FAPEMIG - APQ-01864-12; APQ- 02548-14).
} 
consolidando uma perspectiva sociointeracionista de linguagem - linguagem como prática social - e mesmo legitimando-a nos documentos em que o Estado parametriza este ensino. Nesta direção, definiu-se uma rede integrada de práticas de leitura, escrita e oralidade como meta de ensino da LP. Avanços aconteceram, é fato, na teoria e mesmo na prática, ainda que nesta, de modo lento e minoritário. Nesta rede de saberes propostos, muitos e muitos professores ainda estão emaranhados, sem caminhos para transformar teoria em prática ou mesmo sem compreender tal teoria (MIRANDA, 2005, 2006). Ainda mais: sem saber como construir um ambiente efetivo de linguagem - de atenção de intenção conjuntas - em uma cena em que as vozes, via de regra, se perdem em conflitos ou em bate-papos, sem espaço para a voz e a vez da cada um. E se falta um frame de atenção e intenção conjuntas em sala de aula, envolvendo seus atores como partícipes, a linguagem não acontece e, se não acontece, não se efetiva a construção do conhecimento.

Foi este o cenário mostrado por uma gama de quatro novos estudos de caso sobre a sala de aula de LP que trouxe a voz de discentes (SIQUEIRA, 2013; LOURES, 2013) e docentes (TEIXEIRA, 2014) do ensino médio. Uma consequência marcante ecoou dessas vozes, qual seja a autoimagem negativa dos discentes; o sentimento de incapacidade, de incompetência e o desinteresse desencadeado pela "culpa" pelo fracasso. Mais uma vez, contudo, preserva-se a imagem do professor. No ensino superior, a perspectiva de alunos de um curso de Letras sobre seu processo de formação (LIMA, 2014) completou o "mapa", revelando o desinteresse pela profissão de professor entre aqueles que fazem licenciatura em Letras.

No conjunto, esta rede de pesquisa envolveu dez estudos de caso, desenvolvidos na zona de influência da Universidade Federal de Juiz de Fora (Zona da Mata mineira) em trinta e sete (37) escolas públicas de ensino fundamental e médio. Sete (7) destes estudos tiveram as vozes dos discentes como matéria; dois (2), as vozes docentes; e um (1), a palavra de alunos do curso de Letras.

Os resultados reiterados nesta rede de estudos nos impulsionaram para o terceiro momento do projeto de pesquisa - a sua vinculação às pesquisas de natureza interventiva e participativa do PROFLETRAS (Mestrado Profissional em Letras-FALE/UFJF). Com este viés, temos dois (2) estudos concluídos e dois (2) em andamento e, assim, a travessia se completa, tomando o rumo da ação, buscando o impacto social desejável.

Passamos, de modo abreviado, à elucidação da matriz teórico-metodológica destes estudos, pontuando a motivação de cada escolha (seção 2) e, em seguida (seção 3), à apresentação de um Estudo de Caso (LOURES, 2013) que tem como questão a autoimagem dos alunos de Português em sete escolas da rede estadual de ensino da cidade de Juiz de Fora. Na seção 4, apresentamos as considerações finais.

\section{DAS ESCOLHAS TEÓRICO-METODOLÓGICAS E DE SUAS RAZÕES}

Em torno destes estudos de natureza híbrida ergueu-se uma matriz teóricometodológica que envolve os seguintes aparatos: 
a) o uso das narrativas de práticas (FABRÍCIO; BASTOS, 2009; THORNBORROW; COATES, 2005; DELORY-MOMBERGER, 2008, 2012, 2014, dentre outros) como instrumento investigativo dos Estudos de Caso;

b) a construção de um modelo de análise do discurso baseado na Semântica de Frames (FILLMORE, 1977, 1979, 1982, 1985, 1992, 2009; FILLMORE; JOHNSON; PETRUCK, 2003; SALOMÃO, 1999; MIRANDA; SALOMÃO, 2009; PETRUCK, 1996; GAWRON, 2008; RUPPENHOFER et al., 2010, dentre outros) e nos Modelos de Linguagem Baseados no Uso (TOMASELLO, 2003; CROFT; CRUSE, 2004; GOLDBERG, 1995, 2006; BYBEE, 2010, dentre outros);

c) um diálogo interteórico, voltado para o exercício interpretativo das questões educacionais emergentes em cada Estudo de Caso, com contribuições de áreas do saber como a Antropologia Evolucionista (TOMASELLO,1999, 2003), a Psicologia Social (LA TAILLE, 1999; LA TAILLE; MENIN, 2009), a Sociologia, a Filosofia e a Educação (BAUMAN, 1992, 1998, 1999, 2005, 2007; GIDDENS, 1991, 1992; BERMAN, 2001; APPLE, 2000, 2001, 2002, 2006; BEECH, 2009; FRIGOTTO; CIAVATTA, 2003; MACEDO, 2000; CHAUÍ, 1999, 1997; CUNHA, 2003, 2004, dentre outros).

Tendo como matéria investigativa a perspectiva instaurada pela voz de alunos e professores sobre o cenário escolar e, mais especificamente, sobre a sala de aula, estes Estudos de Caso têm como objeto de análise as narrativas de práticas. Para tal objeto linguístico vimos tecendo um modelo de análise ancorado na categoria frame (Semântica de Frames) e na afirmação do relevo do uso linguístico e de sua frequência na arquitetura de nossa expressão conceptual (Modelos de Linguagem Baseados no Uso).

As hipóteses analíticas traçadas por tal modelo de análise são de que (i) os frames invocados pelo discurso permitirão chegar-se aos indicadores da experiência social da comunidade em estudo e de que (ii) quanto maior for a frequência de cada frame - e das Unidades Lexicais (UL) que os evocam e dos Elementos de Frame (EF) que os constituem (cf. subseção 2.2) - mais vigorosa será a experiência evocada por tais frames. O que se busca, portanto, é explorar a relação entre linguagem e experiência, como passamos a elucidar.

\subsection{A NARRATIVA NÃO É A VIDA COMO O MAPA NÃO É O TERRITÓRIO}

O ato de narrar é, nos termos de Thornborrow e Coates (2005), central à construção de nossa identidade social e cultural, representando uma capacidade fundamental da cognição humana. Nóbrega e Magalhães (2012) e Moita Lopes (2001), convergem nesta visão atribuindo à narrativa "um lócus da (re)construção identitária". Por meio dela os sujeitos dizem quem são, no que acreditam e o que desejam. Também para Rego (2003), as narrativas sobre si mesmo podem expressar um conjunto de significados que foram construídos culturalmente pelo sujeito - “[...] suas visões interpretações, impressões, representações e lembranças [...]" (REGO, 2003, p 80), tornando possível a identificação de traços históricos e culturais internalizados de uma determinada época ou sociedade. 
Este é, pois, o endosso para o uso da narrativa como um meio de captar as vozes dos discentes neste trabalho. Cabe pontuar, contudo, que a narrativa é uma prática discursiva - uma operação cognitiva e um objeto de linguagem específico. "A narrativa seleciona, orienta, ordena, reúne, projeta, seguindo uma lógica a posteriori, que é a do narrador no momento da narração.” (DELORY-MOMBERGER, 2014 [2004], p.179). Não há transparência, portanto, entre o vivido e o narrado, ou seja, a narrativa não é a vida assim como o mapa não é o território. Portanto, no uso da narrativa como estratégia metodológica na construção de dados não nos mobiliza a ilusão da "verdade" a ser desvelada nas aulas de Língua Portuguesa, mas as pistas deixadas pelas escolhas feitas pelo narrador-personagem, pela sua perspectiva na reconstrução, no presente, de uma cena vivida no passado. Nosso propósito não é também apreender as representações e os valores de um indivíduo singular, mas as experiências pessoais que, replicadas de modo significativo, sirvam de indicadores das experiências coletivas mais relevantes do grupo. Do particular ao geral, encontram-se, assim, as figuras - as representações recorrentes em contextos similares - que emergem no conjunto dos discursos.

\subsection{SOBRE O OBJETO LINGUÍSTICO E UM MODELO DE ANÁLISE DO DISCURSO}

É amplamente reconhecido o papel da experiência de todas as ordens na instituição do pensamento e da linguagem dentro dos pilares centrais da Linguística Cognitiva. Nessa direção, os processos de significação construídos em frames de atenção conjunta, o uso linguístico e a diversidade das línguas passam a ocupar a agenda investigativa dos linguistas. De igual modo, os corpora naturais tornam-se uma opção metodológica cada vez mais usada a que se somam as naturais intuições analíticas do linguista.

Assim, subscrevendo tal paradigma e tendo a relação linguagem e experiência como hipótese-guia, este estudo elege como matéria analítica um corpus constituído por narrativas de práticas e define seu escopo teórico-analítico central a partir da Semântica de Frames e de seu projeto lexicográfico computacional, a FrameNet, e dos Modelos de Linguagem Baseados no Uso (cf. item "ii”, seção 2).

O endosso central para uma análise do discurso baseada em frames está nas palavras de Fillmore:

\footnotetext{
Desse modo, pode-se ver a proximidade que existe entre a semântica lexical e a semântica textual ou, para me expressar melhor, entre a semântica lexical e o processo de compreensão do texto. As palavras que evocam frames em um texto revelam a multiplicidade de maneiras com que o falante ou o autor esquematizam a situação e induzem o ouvinte a construir uma tal visualização do mundo textual que motive ou explique os atos de categorização expressos pelas escolhas lexicais observadas no texto. (2009[1982], p. 37)
}

O percurso interpretativo exige, portanto, que se recuperem e percebam os frames evocados pelo conteúdo lexical do texto, combinando esse conhecimento esquemático de modo a construir uma compreensão do mundo textual.

A noção de frame trazida por Fillmore (1977, 1979, 1982, 1985, 1992, 2003) a partir de uma Semântica da Compreensão, de caráter empírico e inferencial, se contrapõe ao 
modelo de análise do significado propugnado por uma semântica composicional (Semântica da Verdade) ancorado em condições necessárias e suficientes. Assim, negando o caráter estritamente composicional do processo de significação - a dita Hipótese Forte da Composicionalidade -, a Semântica de Frames, tendo em conta as motivações que impulsionam uma comunidade de fala a criar determinada categoria representada pela palavra, ultrapassa a materialidade linguística e toma as palavras como categorias de experiência. Este é, pois, o ponto crucial deste modelo semântico que confere continuidade entre linguagem e experiência.

O termo "frame" corresponde "a qualquer sistema de conceitos relacionados de tal modo que para entender qualquer um deles é preciso entender toda a estrutura na qual se enquadram" (FILLMORE, 2009[1982], p. 25). Assim sendo, quando acionamos qualquer elemento de um frame, este evoca consigo uma cena, e é somente nesse enquadre que pode ser compreendido.

Tal relativização dos significados às cenas é, pois, fundamental para a compreensão das diversas perspectivas que se tecem na conceptualização das palavras e discursos. Deste modo, este instrumental teórico vem facultando ao presente estudo o mapeamento dos processos de significação erguidos nos discursos sobre a sala de aula e permitindo a construção de um sólido diagnóstico sobre a perspectiva dos sujeitos acerca da realidade vivenciada.

O projeto lexicográfico derivado desta teoria - a FrameNet - empresta a este estudo as principais ferramentas analíticas.

Baseado na Semântica de Frames, a FrameNet é um projeto lexicográfico computacional desenvolvido na Universidade de Berkeley

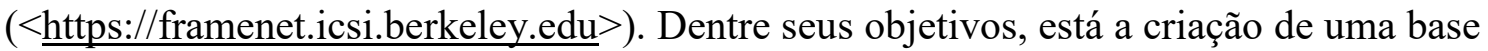
de dados de palavras do Inglês (e de outras línguas, como o Português) ${ }^{3}$ e dos frames que elas evocam, além da documentação de possibilidades combinatórias sintáticas e semânticas de cada palavra em cada um dos seus sentidos. Essas descrições que compõem o banco de dados estão baseadas em anotações semânticas de exemplos de sentenças extraídas de grandes corpora de textos (BAKER; FILLMORE; LOWE, 1998; FILLMORE; JOHNSON, 2000; FILLMORE; JOHNSON; PETRUCK, 2003).

Salomão (2009) aponta uma vantagem deste projeto sobre a abordagem lexicográfica tradicional. Por meio dele, é possível obterem-se as informações que no dicionário só aparecem implicitamente. Isso ocorre porque a consulta a uma palavra remete ao frame que esta evoca e a todos os elementos que o integram. Além disso, é permitido ainda o acesso às possibilidades de combinação sintáticas e semânticas da palavra pesquisada, e o acesso a outros frames que se relacionem com o frame buscado.

Para análise de corpus, a FrameNet criou categorias como a Unidade Lexical e o Elemento de Frame. A Unidade Lexical (UL) "é um pareamento de uma palavra com um

\footnotetext{
${ }^{3}$ Outros projetos aos moldes da FrameNet têm sido desenvolvidos para outras línguas como alemão, japonês, espanhol, português e sueco. Para o português, temos a FrameNet Brasil

$(<$ http://www.ufjf.br/framenetbr/>), projeto de notação lexicográfica desenvolvido na Universidade Federal de Juiz de Fora.
} 
significado" (FILLMORE; JOHNSON; PETRUCK, 2003, p. 9). Cada sentido de uma palavra evoca um frame e os elementos que compõem a estrutura da cena, sendo as palavras polissêmicas evocadoras de frames diferentes dependendo de seu sentido. Já os Elementos de Frame (EF) são os participantes de uma cena evocada (micropapéis semânticos), e podem constituir-se como centrais ou não centrais (RUPPENHOFER et al., 2010).

Tomando, como exemplo, o frame Aplicar_calor (RUPPENHOFER et al., 2010), temos possíveis ULs como "assar", "ferver" evocadoras de uma cena com os EFs Cozinheiro, Comida e Instrumento_de_aquecimento.

A análise feita nesta plataforma implica a reconhecimento da estrutura argumental na unidade frasal, o que envolve a notação em três níveis de função, quais sejam a semântica (Elementos de Frames), a função gramatical (FG) e o tipo de sintagma (TS).

Há diferentes tipos de relações semânticas entre os elementos incorporados na base de dados da FrameNet. Essas relações são diretas (assimétricas) e se dão, como pontuam Ruppenhofer et al. (2010), entre dois frames em que um deles (o menos dependente, mais abstrato) é chamado de superframe enquanto o outro, mais dependente, é um subframe. Essas relações, primeiramente, frame a frame, como pontua Fillmore (2003), podem ser: Subframes, Herança, Perspectiva_em, Veja_também, Usando, Incoativo_de e Causativo_de. É possível a consulta das relações entre os frames por meio da ferramenta Framegrapher, disponível no site.

Outra opção teórica para o modelo de análise do discurso que se tece em nosso projeto são os Modelos de Linguagem baseado no Uso (item ii). O cerne teórico de tais Modelos está na afirmação de que a aquisição e a aprendizagem da linguagem se dão através de exemplares específicos usados em situações comunicativas determinadas e de generalizações construídas a partir do uso reiterado destes exemplares. Dado o relevo da reiteração de uso para a compreensão da forma como a linguagem é estruturada e armazenada na mente do falante, a frequência de token/ocorrência (frequência com que determinada estrutura ocorre em uma determinada comunidade linguística) e a frequência de type/tipo (frequência com que essa mesma estrutura varia dentro do mesmo grupo de falantes) ganham relevo nas análises orientadas por tais Modelos. A primeira implica a assertiva de que quanto mais frequente uma forma for, mais entrincheirada, mais central à língua ela será, articulando-se com a noção de Convencionalização; a segunda relaciona-se à possibilidade de extensão de um padrão a novos padrões, vinculando-se ao conceito de Produtividade.

Guardadas as especificidades de cada Estudo de Caso, os seguintes passos definem a matriz de procedimentos analíticos seguida (MIRANDA; BERNARDO, 2013):

a) Anotação manual ${ }^{4}$ de Unidades Lexicais (UL) que são eleitas com auxílio da ferramenta WordSmithTools através dos recursos Wordlist (fornecendo a lista completa de ocorrências de cada palavra do texto, assim como sua frequência, tal ferramenta permite, a partir da pergunta de cada Estudo de Caso, eleger as

\footnotetext{
${ }^{4}$ As anotações feitas nestes estudos têm sido manuais; em apenas um (1) estudo de caso conseguimos usar o desktop da FrameNet. 
ULs a serem recortadas) e Concordance (busca do contexto de uso das ULs eleitas);

b) Evocação dos frames (busca no repertório da FrameNet) que as ULs invocam;

c) Descrição dos frames não encontrados na FrameNet;

d) Anotação de Elementos do Frame (EF);

e) Desenho da rede de frames (framegraphers);

f) Estabelecimento de frequência de types/tokens em relação aos frames, às Unidades Lexicais e aos Elementos de Frame que integram cada frame;

g) Exercício interpretativo dos discursos, mediante diálogo interdisciplinar construído a partir da questão posta em cada Estudo de Caso (cf. item "iii", seção 2).

Passamos à apresentação de um Estudo de Caso de modo a ilustrar a matriz teórico-metodológica eleita neste macroprojeto.

\section{UM ESTUDO DE CASO - A AUTOIMAGEM DO ALUNO DE LÍNGUA PORTUGUESA}

Como um projeto vinculado à rede investigativa apresentada à Introdução, este estudo de caso (LOURES, 2013) tem como aporte a matriz teórico-metodológica apresentada à seção 2. O que o distingue é questão específica que o mobiliza, qual seja Como os sujeitos investigados constroem sua identidade enquanto alunos de Língua Portuguesa?

O propósito analítico é, pois, mapear a autoimagem desses discentes, valendo-nos, para tanto, da análise do discurso desses sujeitos sobre suas experiências nas aulas de Português. Dos indicadores levantados nesta análise decorre o exercício interpretativo, o que traz também a singularidade do campo interteórico a ser buscado. Em nosso caso, contribuem para a interpretação dos resultados semânticos auferidos pela análise em frames os estudos de MIRANDA, 2007, 2009, 2011; PEREIRA, 2008; LIMA, 2009; PINHEIRO, 2009; BERNARDO, 2011; ALVARENGA, 2012; FONTES, 2012.

O lócus investigativo é a sala de aula de Língua Portuguesa de sete escolas da rede estadual de Ensino de Juiz de Fora. Os sujeitos são cento e oitenta e oito (188) alunos do nono ano do Ensino Fundamental e do segundo ano do Ensino Médio, o que representa $35 \%$ da mostra total (trezentos e sessenta e quatro - 364 - alunos, com um total de trezentos e quarenta - 340 - respostas válidas).

De modo a se evitar uma realidade homogênea, as escolas foram escolhidas segundo determinados critérios. O primeiro critério constituiu-se a partir do mapeamento das instituições em termos dos resultados obtidos no IDEB e na Prova Brasil, assim como da análise de dados como taxa de abandono, taxa de reprovação, média de alunos por turma e taxa de participação dos alunos no Enem. Desse modo, a pesquisa contempla escolas com qualificações alta, média e baixa em todos esses quesitos. O segundo critério baseou-se na distribuição geográfica heterogênea das escolas (duas localizadas na região norte, três na região central, uma na região sul e uma na região oeste da cidade), o que implica envolver regiões com riscos sociais distintos. 
Em seu âmbito metodológico, este estudo, caracterizando-se como um estudo de caso $^{5}$, precisa pontuar, de pronto, o alcance das generalizações analíticas alcançadas por seus resultados, circunscrevendo-as ao limite do universo investigado.

O trabalho apresentado resultou em uma rede de frames que identificados, hierarquizados e analisados, trouxeram à luz quatorze (14) indicadores analíticos que, no conjunto, desenharam o retrato da autoimagem discente.

Dados os limites de espaço deste artigo, procederemos a uma apresentação abreviada dos resultados gerais obtidos para nos determos no INDICADOR 2, um dos mais relevantes (e, talvez, mais preocupantes) dentre os encontrados em nosso trabalho.

Como já referenciado à seção 2 , o instrumento de coleta utilizado nos estudos de caso de nosso macroprojeto tem sido uma narrativa de experiência. Em nosso caso, tal instrumento assim se delimita:

\begin{abstract}
Caro Aluno,
A disciplina de Língua Portuguesa está presente em sua vida desde que você entrou para a escola. Durante este tempo, você vivenciou várias experiências relacionadas à matéria (com seus professores, durante suas aulas, conteúdos que aprendeu etc.). Gostaríamos, então, de conhecer um pouco da sua história e compreender melhor sua relação com essa disciplina. Conte-nos suas vivências mais marcantes (positivas ou negativas) como aluno de Português.
\end{abstract}

Os destaques em negrito demarcam os limites do discurso desejado - relatar as experiências mais importantes com a disciplina Língua Portuguesa e avaliá-las (de maneira positiva ou negativa), assim como já delimitam os superframes a serem evocados: o frame de Ensino_educação e o frame de Aula_de_Português.

A análise do discurso discente, seguindo os procedimentos anunciados à seção 2, partiu, portanto, do levantamento das principais as unidades lexicais (ULs) e construcionais (UCs) evocadoras. Somada a tal procedimento, outra pista usada foram os atos de linguagem expressos nos relatos de experiência discentes que remeteram às seguintes práticas discursivas em relação à disciplina de Língua Portuguesa:
a) Expressão de sentimentos;
b) Autoavaliações;
c) Relatos de experiências.

\footnotetext{
${ }^{5}$ Segundo Yin (2001), o estudo de caso é uma metodologia utilizada para explorar situações da vida real, debruçando-se, de maneira mais aprofundada, sobre um acontecimento contemporâneo. O principal objetivo de tal abordagem não é descrever o objeto analisado, mas explicá-lo e, por essa razão, várias técnicas de pesquisa são conjugadas neste processo. O estudo de caso possui, assim, um grande potencial no âmbito educacional, uma vez que se orienta por perguntas (do tipo "como" e "porque") e não por soluções.
} 
A partir de tais procedimentos, uma complexa rede de frames nos permitiu traçar a autoimagem do aluno de Português no cenário escolar investigado. É o que passamos a sintetizar:

a) Ao superframe Aula_de_Português vinculam-se quatro (4) frames: Autoavaliação_comportamento_escolar, Autoavaliação_desempenho_escolar (hierarquicamente subordinados também ao superframe Autoavaliação), Relatos_de_experiência_escolar e ....Foco_no_experienciador;

b) Por sua vez, ao frame Autoavaliação_comportamento_escolar vinculam-se quatro (4) outros frames: Dedicação, Experiência_de_encontro_hostil, Prestar_atenção e Bagunça;

c) Seis (6) frames se subordinam a Autoavaliação_desempenho_escolar: Capacidade, Compreensão, Dificuldade, Tentativa, Impedimento, Sucesso e Fracasso;

d) Os estudantes que elegeram os Relatos_de_experiência_escolar como foco principal de sua narrativa, acionaram os frames de Experiência_de_criação_textual, Experiência_de_expulsão, Experiência_de_teatro, Experiência_de_avaliação_e_resultado e Experiência_de_leitura.

O gráfico 1 sintetiza a distribuição por frequência dos superframes principais que suportam a rede em nosso corpus. O número total de segmentos considerados para o cálculo das ocorrências (duzentos e setenta e sete - 277) ultrapassa o número total de alunos (cento e oitenta e oito - 188), uma vez que alguns segmentos aparecem em mais de um frame analisado, sendo contados duplamente.

\section{Gráfico 1 - Distribuição dos principais macroframes analisados}

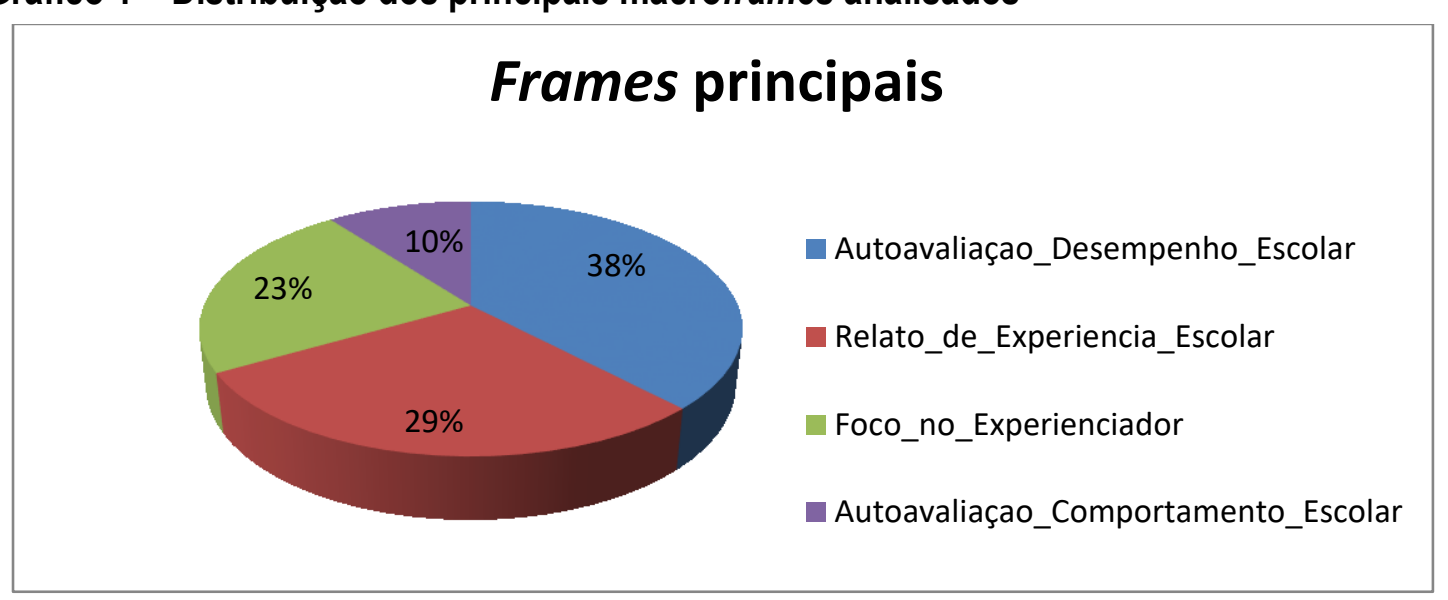

O diagrama 1 de toda a rede (cf. Fluxograma 1) dá uma dimensão da complexidade do processo de construção da autoimagem desses alunos. Ao descreverem a si mesmos, os estudantes evocam cenas distintas, utilizando diferentes tipos textuais (divididos em superframes): 
Diagrama 1 - A autoimagem dos alunos de Língua Portuguesa

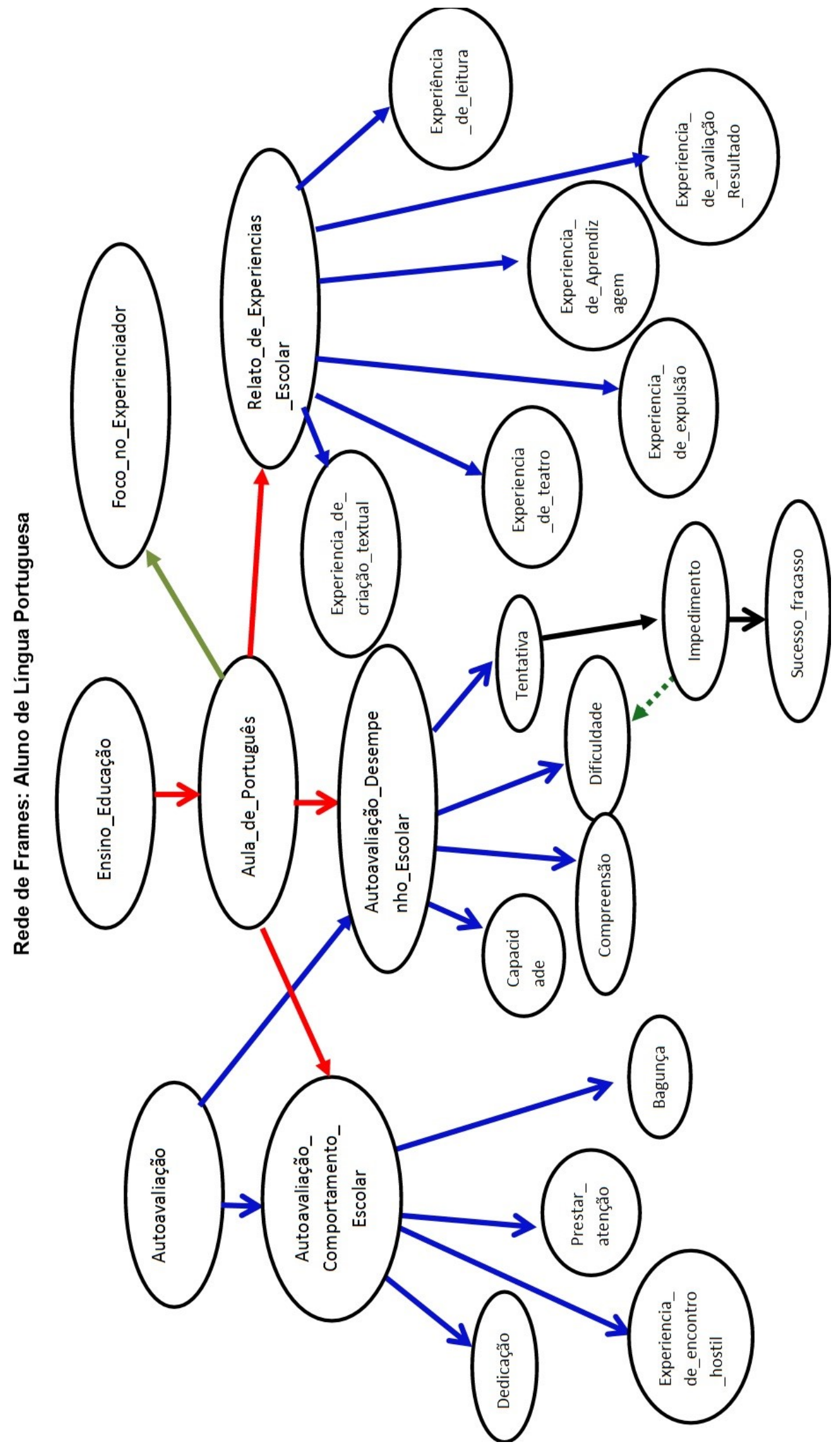


Após a análise semântica detalhada desta rede, quinze importantes indicadores sintetizam as principais generalizações analíticas alcançadas neste Estudo de Caso (Tabela 1):

\section{Tabela 1 - Os indicadores analíticos}

\begin{tabular}{|c|c|c|}
\hline Superframes & Frames & INDICADORES \\
\hline $\begin{array}{l}\text { Foco_no_- } \\
\text { experienciador } \\
\qquad 23 \%\end{array}$ & $\begin{array}{l}\text { 4MA2- } 3 \mathrm{Eu} \text { particularmente } \\
\text { detesto português, pois nunca } \\
\text { entendo a matéria }\end{array}$ & $\begin{array}{l}\text { A relação afetiva estabelecida com a } \\
\text { disciplina Língua Portuguesa é de } \\
\text { significativo afastamento e mesmo de alta } \\
\text { rejeição - } 61,8 \% \text { das expressões de sentimento } \\
\text { são negativas. }\end{array}$ \\
\hline \multirow{4}{*}{$\begin{array}{l}\text { Autoavaliação } \\
\text { desempenho } \\
\text { Escolar }\end{array}$} & $\begin{array}{l}\text { Dificuldade }(48 \%) \\
\text { 5MA2-22- Não sou uma boa aluna } \\
\text { nessa } \\
\text { matéria,tenhomuitadificuldade. Não } \\
\text { entendo quase nada.Minha } \\
\text { professora é ótima explica super } \\
\text { bem, mas acho que o problema } \\
\text { está comigo. }\end{array}$ & $\begin{array}{l}\text { 2) A segunda relação estabelecida é a de } \\
\text { dificuldade. Dentre os estudantes que acionam } \\
\text { este frame, } 87,5 \% \text { relatam tal relação e } \\
\text { atribuem a culpa desta dificuldade a si } \\
\text { mesmos. }\end{array}$ \\
\hline & $\begin{array}{l}\text { Compreensão }(24 \%) \\
\text { 6MA2-28 Não gosto de } \\
\text { portuguêsnão entendonada.IND }\end{array}$ & $\begin{array}{l}\text { 3) } 60 \% \text { dos trinta e cinco (35) } \\
\text { estudantes que acionam o frame de } \\
\text { Compreensão não entendem ou entendem } \\
\text { pouco a disciplina. }\end{array}$ \\
\hline & $\begin{array}{l}\text { Capacidade }(11 \%) \\
\text { 5MA9- } 11 \text { Para falar a verdade } \\
\text { nunca gostei de português, tenho } \\
\text { muita dificuldade em entender, em } \\
\text { memorizar as regras, mas com } \\
\text { muitas dificuldadesconsigotirar } \\
\text { notas médias.IND }\end{array}$ & $\begin{array}{l}\text { Os alunos sentem-se incapazes diante } \\
\text { da disciplina; } 63 \% \text { dos estudantes que } \\
\text { acionam o frame, dizem não conseguir } \\
\text { compreender a disciplina. }\end{array}$ \\
\hline & $\begin{array}{l}\text { Tentativa (6\%) } \\
\text { Impedimento (3\%) } \\
\text { Sucesso ou Fracasso }(8 \%) \\
\text { 4MA2 - 8 No meu caso eu sempre } \\
\text { tive um pouco de dificuldade no } \\
\text { entendimento da matéria mas com } \\
\text { um pouquinho de esforço eu } \\
\text { conseguia boas notas. (...) segundo } \\
\text { são os próprios alunos, somos nós } \\
\text { mesmos que atrapalhamoso } \\
\text { rendimento da aula. }\end{array}$ & $\begin{array}{l}\text { 5) Mesmo quando fala de seu sucesso } \\
\text { (8\%), o estudante apresenta suas tentativas } \\
\text { juntamente aos impedimentos que } \\
\text { encontraram neste percurso, o que demonstra } \\
\text { que tal sucesso não foi conseguido facilmente. }\end{array}$ \\
\hline $\begin{array}{l}\text { Autoavaliação } \\
\text { _comportamento } \\
\text { _escolar }\end{array}$ & $\begin{array}{l}\text { Bagunça }(33 \%) \\
\text { 6MA9-18Pow nem tenho tanta } \\
\text { coisa pra falar porque nas } \\
\text { aulas[IND] faço só bagunça. Mas }\end{array}$ & $\begin{array}{l}\text { 6) Os relatos de bagunça durante as } \\
\text { aulas pautam suas justificativas na facilidade } \\
\text { de aprendizagem da disciplina, o que sinaliza } \\
\text { a ausência de desafios neste processo de } \\
\text { ensino-aprendizagem para este grupo. }\end{array}$ \\
\hline
\end{tabular}




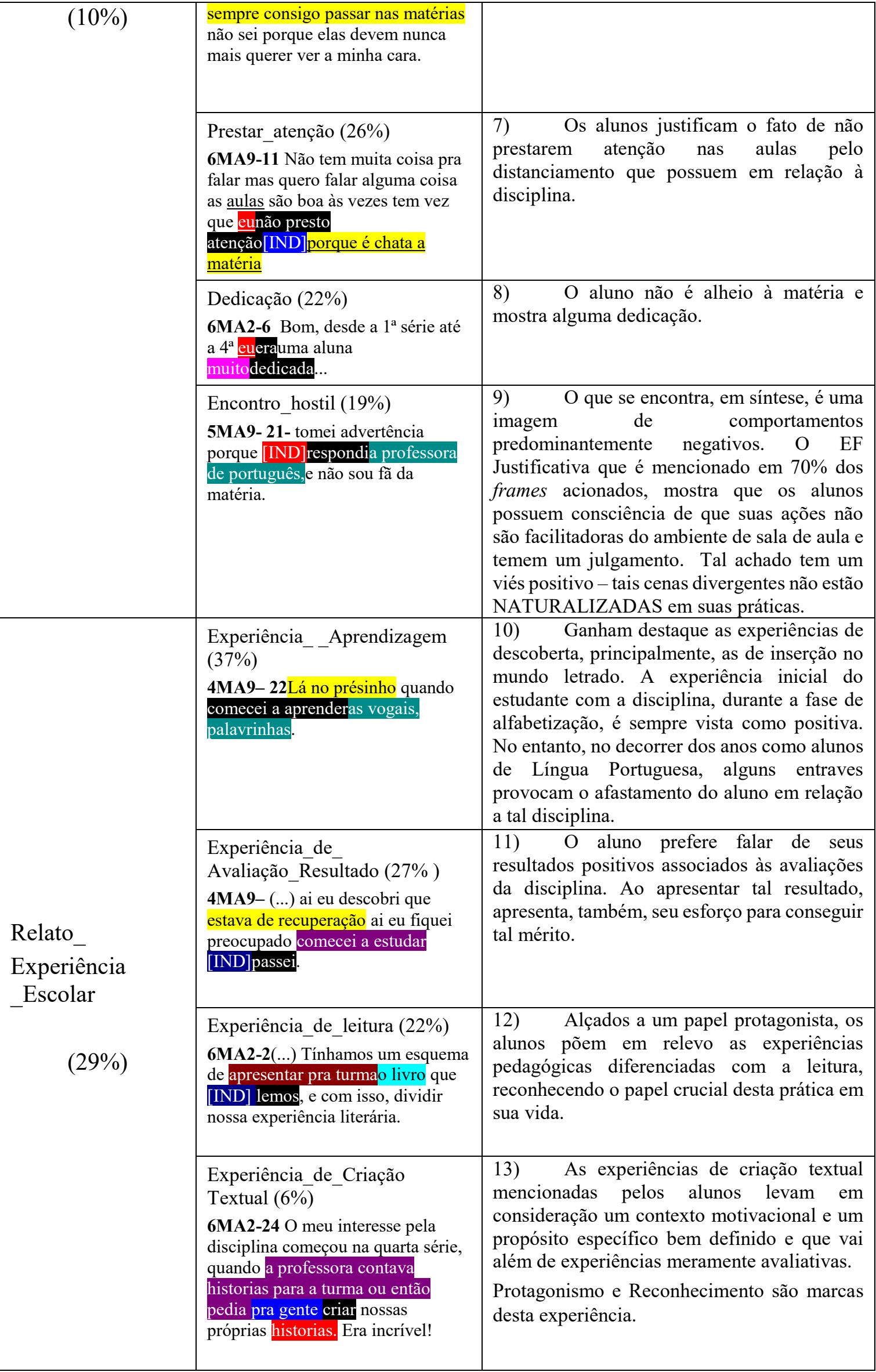




\begin{tabular}{|l|l|l|}
\hline & $\begin{array}{l}\text { Experiência_de_Teatro (5\%) } \\
\text { 5MA2-17 (...) aí eu participei do } \\
\text { teatro que tinha na escola minha } \\
\text { vida mudou pra melhor. }\end{array}$ & $\begin{array}{l}\text { 14) As experiências de teatro, mesmo em } \\
\text { percentual menor que as demais, representam } \\
\text { um motivador de protagonismo e autoestima } \\
\text { para o aluno. }\end{array}$ \\
\cline { 2 - 4 } & $\begin{array}{l}\text { Experiência_de_Expulsão (3\%) } \\
\text { 4MA2-22 No ano passado tive a } \\
\text { experiência de ser expulsa de } \\
\text { salapor motivo de conversa }\end{array}$ & $\begin{array}{l}\text { 15) O frame de expulsão sempre representa } \\
\text { uma experiência negativa. Nos dois casos } \\
\text { analisados, o aluno apresenta consciência } \\
\text { sobre o motivo que levou a sua expulsão. }\end{array}$ \\
\hline
\end{tabular}

Como pode ser observado na Tabela 1 , um número considerável de relatos aciona o frame de Dificuldade (48\%) hierarquicamente subordinado a Autoavaliação _desempenho _escolar. Por isso, tal frame foi eleito para um exercício interpretativo um pouco mais detalhado nesse artigo.

\subsection{FRAME DE DIFICULDADE}

Dificuldade

( $<$ https://framenet2.icsi.berkeley.edu/fnReports/data/frameIndex.xml?frame $=$ Difficulty $>$ ) é o frame mais acionado pelos discentes: aparece em cinquenta e quatro (54) segmentos e é evocado cinquenta e sete (57) vezes por distintas ULs e UCs, o que representa 48\% do grupo Autoavaliação_Desempenho_escolar (em cinquenta e quatro 54 - segmentos).

Esse frame define-se pela ideia de um experienciador que apresenta dificuldade ou facilidade para realizar determinada tarefa. Sua descrição, retirada da FrameNet e traduzida por nós, é a seguinte:

\section{Quadro 1 - Frame de Dificuldade}

\section{Frame de Dificuldade}

Um experienciador tem facilidade ou dificuldade na realização de uma atividade A facilidade ou dificuldade de uma atividade parece ser às vezes acionada por um participante proeminente. Entretanto, consideramos que esta impressão se dá devido à sintaxe e à pragmática das construções e não empregamos nenhum EF especial para esses participantes. A gradação da facilidade ou dificuldade é frequentemente especificada por uma circunstância. $\mathrm{O}$ Parâmetro, que indica porque a atividade é considerada fácil ou difícil, pode ser mencionado.

\section{EFs Centrais:}

Atividade Indica a Atividade em que o Experienciador encontra dificuldade ou facilidade. Em alguns casos, a Atividaderelevante tem que ser inferida a partir do contexto.

Apesar deu gosta de Português tenho minhas dificuldades em tirar notas boas

Eu sinto um pouco de dificuldadeem relação à Língua Portuguesa 
Experienciador: Indica que uma pessoa julga a realização de uma Atividade difícil ou fácil.

\section{Euaté hojetinhauma certadificuldade.}

Eutenhomuitadificuldadede aprender.

\section{Não-Central:}

Grau : Indica o Grau de dificuldade que o Experienciador possui para a realização de uma Atividade.

Gosto muito da matéria, mas[IND]tenho grandes dificuldades para estudar

Tempo :O Tempo em que a Atividade ocorre.

No Ensino Fundamental eu achava fácil sempre tirava boas notas. Mas no Ensino Médioencontrei um grau de dificuldade maior.

Unidades Lexicais e Unidades Construcionais: difícil n, dificuldade n, , complicado n., sentir dificuldade $\mathrm{v}$, fácil $\mathrm{n}$, facilidade $\mathrm{n}$. sentir dificuldade

No corpus analisado, foram encontradas quatro (4) ULs e quatorze (14) UCs distintas evocadoras do frame Dificuldade. Tais unidades são apresentadas no quadro a seguir, dividido por sinsets, ou seja, por listas de sinônimos de unidades lexicais e construcionais. Ao lado desta coluna, temos os tokens (frequência de ocorrências):

\section{Quadro 2 - Frame Dificuldade: Unidades Lexicais e Unidades Construcionais}

\begin{tabular}{|c|c|c|c|c|}
\hline \multicolumn{5}{|c|}{ Ucs e ULs Frame Dificuldade } \\
\hline \multirow{3}{*}{$\begin{array}{l}\text { Semântica } \\
\text { negativa }\end{array}$} & & & Tokens & Exemplos \\
\hline & Sinset 1 & $\begin{array}{l}\text { Sentir } \\
\text { dificuldade, ter } \\
\text { dificuldade, } \\
\text { encontrar } \\
\text { dificuldade, ter } \\
\text { problema, } \\
\text { difícil, } \\
\text { complicado }\end{array}$ & 36 & $\begin{array}{l}\text { 5MA9- 16- Apesar deu gosta de Português } \\
\text { tenho minhas dificuldades em tirar notas boas! } \\
\text { 6MA2-9 Mas no Ensino Médioencontrei um } \\
\text { grau de dificuldademaior.[IND] }\end{array}$ \\
\hline & Sinset 2 & $\begin{array}{l}\text { Ficou difícil, } \\
\text { começou a } \\
\text { ficar difícil, } \\
\text { ficou } \\
\text { complicado }\end{array}$ & 10 & $\begin{array}{l}\text { 7MA9 - } 13 \text { Mas na quinta série começou ficar } \\
\text { um pouco difícil pois a turma não colaborava, } \\
\text { os professores não tinham paciência. } \\
\text { 4MA9-6 Mas o tempo foi passando e } \\
\text { português foi ficando mais complicado não sei } \\
\text { se é difícil ou se }\end{array}$ \\
\hline & \multicolumn{3}{|c|}{ Subtotal: $46(79,31 \%)$} & \\
\hline $\begin{array}{l}\text { Semântica } \\
\text { Positiva }\end{array}$ & Sinset 3 & $\begin{array}{l}\text { Nunca ter } \\
\text { dificuldade, } \\
\text { nunca ter } \\
\text { problema }\end{array}$ & 4 & $\begin{array}{l}\text { 4MA2-4 Desde pequeno nunca tive } \\
\text { dificuldade quanto à matéria de português }\end{array}$ \\
\hline
\end{tabular}




\begin{tabular}{|l|l|l|l|l|}
\hline & & & $\begin{array}{l}\text { 5MA2-9Bem, desde que comecei a estudar } \\
\text { nunca tive nenhum problema com a Língua } \\
\text { Portuguesa }\end{array}$ \\
\cline { 2 - 5 } & Sinset 4 & $\begin{array}{l}\text { Não é difícil, } \\
\text { nunca foi } \\
\text { difícil }\end{array}$ & 2 & $\begin{array}{l}\text { 5MA2-1Pra mim,estudar a matéria de } \\
\text { português nunca foi difícil }\end{array}$ \\
& Sinset 5 & $\begin{array}{l}\text { Fácil, } \\
\text { facilidade }\end{array}$ & 6 & $\begin{array}{l}\text { 5MA2-8porque já estou ficando muito triste } \\
\text { com meu desempenho melhor porque } \\
\text { português não é uma matéria difícil }\end{array}$ \\
\hline & $\begin{array}{l}\text { 6MA2- No Ensino Fundamental eu achava } \\
\text { fácil sempre tirava boas notas } \\
\text { 5MA2- Tenho facilidade de aprender a matéria } \\
\text { e ainda ajudo alguns colegas quando estão com } \\
\text { dúvida }\end{array}$ \\
\hline & Subtotal: $12(20,7 \%)$ & \\
\hline
\end{tabular}

O quadro 2 mostra que os sinsets que remetem a dificuldade são mais recorrentes, apresentando quarenta e seis (46) ocorrências, o que representa 79,3\% das ocorrências no frame Dificuldade. Em contrapartida, os sinsets de facilidade representam apenas 20,7\% das ocorrências totais.

Uma análise mais detalhada dos EFs não centrais nos deu a dimensão da dificuldade dos alunos. O EF Atividade refere-se em 60,4\% à disciplina de Português e a uma lista de sinônimos que remetem à matéria, assim como a ações e a processos ligados à disciplina (como estudar, compreender e entender) que representam uma forte barreira para processo de aprendizagem destes alunos. Sem sequer reconhecer o propósito educativo do estudo da Língua Portuguesa, os alunos, neste processo de autoavaliação, atribuem a culpa da "não-aprendizagem" a si mesmos, como pode ser observado no segmento abaixo, em que o professor é avaliado de modo positivo em detrimento da autoavaliação negativa:

1. 4MA2-21 Sempre tive ótimos professores, mas nunca consegui aprender muito. Português é a matéria em que eu tenho mais dificuldade.

2. 5MA2-22 Não sou uma boa aluna nessa matéria, tenho muita dificuldade.

i. Não entendo quase nada.

ii. Minha professora é ótima explica super bem, mas acho que o problema está comigo.

Os resultados destacam, em consonância ao primeiro indicador, e de modo claro, o quanto pode ser árdua e mesmo dolorosa a tarefa de aprendizagem em relação à disciplina Língua Portuguesa. O primeiro indicador encontrado foi o 'desafeto' (frame Foco_no_ Experienciador, 23\% em sessenta e cinco (65) segmentos; o segundo, por sua vez, indica 'dificuldade' de aprendizagem (cf. Tabela 1).

A análise desse frame tão recorrente (Dificuldade) não destoa dos demais pertencentes ao superframe Autoavaliação_de_desempenho_escolar. Os resultados 
traduzem uma autoimagem profundamente marcada pela dificuldade, incapacidade, pela tentativa e pelo fracasso escolar.

Esta questão em relação à disciplina é abordada por Perini (2000). O autor discute o motivo que leva tal matéria a ser considerada como "aquela que ninguém aprende". Ele salienta o fato de existirem outras disciplinas tão ou mais complicadas do que o Português e, entretanto, as reações de repugnância recaírem mais fortemente sobre essa disciplina e, em especial, sobre seu ensino de gramática. Calcada em uma repetição do mesmo conteúdo, por anos e anos, a sala de aula de LP estaria condenada ao tédio e à desaprendizagem - esta é a razão apontada pelo linguista.

O que o linguista aponta é o mesmo que os alunos avaliam em seus discursos:

3. 7MA2-30 Bom, a minha vivência com a língua Portuguesa nem sempre é muito boa, pelo fato de ter um pouco de dificuldade as vezes.

A língua Portuguesa não é uma matéria fácil de se lidar de se aprender, é preciso ter um ensino qualificado, onde nós passamos dificuldades quando, fazemos um vestibular, provas para concurso onde nos deparamos com palavras novas fora do nosso cotidiano.

4. 3MA9-3 Aaa, não gosto muito de português... A língua portuguesa me ajudou na fala correta e está me preparando para me ajudar no futuro. Desde pequena tive os melhores professores de português.

Eu acho a matéria muito complicada, pois tenho dificuldade em VTD, VTI, conjunção, conjugação, subordinativas, etc.

Acho que eu também tenho que forçar meu estudo.

Português é complicado de maiiis, mas eu vou indo nessa porque isso não ser necessário no meu dia a dia.

(Obs.: eu não sei me expressar muito bem)

5. 3MA9-7 Eu acho que a disciplina de Português vai pela cabeça de cada um, pois cada um tem sua opinião uns gostam outros detestam, mas fazer o que se essa disciplina foi criada apenas para nos ajudar.

Eu não gosto muito de Português, acho meio chatinho, complicado. Desde quando comecei a estudar sempre peguei os melhores professores de português.

Para esses estudantes, a disciplina de Língua Portuguesa é apresentada como um dos "pacotes de conhecimentos" (BAUMAN, 2008) que não sabem como "desempacotar". O reconhecimento da dificuldade da disciplina e as tentativas de aprendizagem (Indicador 5, 6MA2-7 Eu sempre me esforcei na matéria, mas quase nunca tiro notas boas.) podem demonstrar que os estudantes não buscam atalhos, mas podem desistir ante os obstáculos.

Dado o fato de o conjunto de frames majoritariamente marcado pela perspectiva negativa integrar $71 \%$ de todas as sequências discursivas em foco neste estudo, temos um resultado que confirma que o processo ensino-aprendizagem de LP está longe de atingir as metas propugnadas tanto pela academia quanto pelo Estado. De igual modo, as mesmas vozes adultas conhecem os desafios ainda não superados neste ensino. Pode parecer, à primeira vista, portanto, que o quadro que tecemos representou um "chover no molhado". Contudo, o desafio posto neste estudo foi conhecer a perspectiva discente acerca de 
tal realidade. $\mathrm{O}$ que temos como resultado primeiro, e majoritário, é a comprovação, pelas próprias vozes adolescentes, da construção de uma identidade social marcada pela impotência e pelo fracasso ante a língua pátria:

6. 2MA9-9 [...] Mas tenho que fazer um esforço para aprender pois a matéria é uma das mais importantes para o meu futuro, eu tento ao máximo aprender mas eu nunca consigo entender nada.

Nosso estudo apresentou também uma contraparte positiva advinda do superframe Experiência_Escolar (esse grupo apresentou majoritariamente experiências positivas). Temos, nesse caso, o relato de significativas experiências vinculadas à aprendizagem inicial da disciplina (ciclos de alfabetização), à leitura, ao reconhecimento através das notas, à criação textual e ao teatro. A marca do sucesso em tais vivências remete, de modo claro, ao espaço dado ao Protagonismo e ao Reconhecimento dos discentes.

Por fim, cabe reconhecer que, mesmo em tempos de liquidez (BAUMAN, 2008) e de fugacidade do conhecimento em que a educação é vista, em grande escala, como mercadoria, como bem descartável, nossos alunos ainda buscam por novas identidades construídas por meio da escola. E mesmo pertencendo a uma classe social vítima de uma escola brasileira "interrompida" tantas vezes e cujo projeto continua inacabado e devedor, esses sujeitos ainda reproduzem a ideia do poder transformador da escola, ainda carregam uma esperança transmitida, certamente, pelos pais que tiveram menos chances ainda que seus filhos:

7. 5MA2-15 Desde pequena sempre gostei de estudar, pois sempre tive o objetivo de dar uma vida melhor a minha família. Meus familiares não tiveram uma escolaridade boa, mas porém sempre me incentivaram a estudar para ter um futuro melhor.

\section{CONSIDERAÇÕES SOBRE OS RESULTADOS DE UMA TRAVESSIA DIFICULTOSA}

Para encerrar este artigo, cabe-nos retomar a epígrafe eleita "Quem elege a busca não pode recusar a travessia" (BOSI, 2003), de modo a aclarar suas razões. O fato é que a narrativa que construímos em uma década acabou por traçar o rumo de uma difícil travessia, qual seja a vinculação deste estudo ao novo projeto brasileiro de qualificação de professores de Português da escola pública - o Mestrado Profissional em Letras (PROFLETRAS/ UFJF). Envolvendo professores do ensino fundamental como pesquisadores-participantes, os novos Estudos de Caso (BRASIL, 2015; ISHIKAWA, 20156) passam a se definir pela pesquisa-ação (MORIN, 2004). A busca destes professores pesquisadores - valendo-se da matriz teórico-analítica construída pela rede de estudos anteriores e também dos resultados por ela alcançados - envolve desde o traçado de um "mapa da crise" de suas salas de aula até a construção de novas tecnologias

\footnotetext{
${ }^{6}$ Há mais outros dois estudos de caso em andamento no PROFLETRAS com conclusão prevista para novembro, 2016. 
de ensino-aprendizagem de Língua Portuguesa, de modo a se enfrentar o ambiente de desinteresse e de incivilidade vivenciado.

Assim, a travessia deste grupo de pesquisadores, da teoria à ação educativa, permitiu que as generalizações analíticas alcançadas, dentro dos limites claros do conjunto de Estudos de Caso, trouxessem significativos elementos para a compreensão da realidade educacional na zona de influência da UFJF e para o trabalho de formação de professores nesta realidade.

Outro ganho substancial nesta travessia investigativa é a consolidação de um modelo de análise do discurso suportado pela Semântica de Frames e pelos Modelos de Linguagem baseados no Uso. Ancorado na relação entre linguagem e experiência, tal modelo traz a vantagem de colocar à mostra e à luz de nosso exercício interpretativo a perspectiva instaurada pelas vozes dos atores centrais da sala de aula sobre as experiências vivenciadas nesse cenário.

\section{REFERÊNCIAS}

ALVARENGA, M. Equação entre educação de valores e educação da oralidade no ensino fundamental. 2012. 142 f. Dissertação (Mestrado em Linguística) - Programa de Pós-graduação em Linguística, Universidade Federal de Juiz de Fora, Juiz de Fora, 2012.

APPLE, M. "Endireitar" a educação: as escolas e a nova aliança conservadora. Currículo sem fronteiras, v. 2, n. 1, jan./jun. 2002. Disponível em: <www.curriculosemfronteiras.org> . Acesso em: 3 jan. 2012.

Ideologia e currículo. Porto Alegre: Art Med, 2006.

Política cultural e educação. São Paulo: Cortez, 2000.

Reestruturação educativa e curricular e as agendas neoliberal e neoconservadora - Entrevista com Michael Apple. Currículo sem fronteiras, v. 1, n. 1, jan./jun. de 2001. Disponível em:

$<$ www.curriculosemfronteiras.org $>$. Acesso em: 3 jan. 2012.

BAKER, C. F., FILLMORE, C. J.; LOWE, J. B. The Berkeley FrameNet Project. International Computer Science Institute: Berkeley, California, 1998. Disponível em:

$<$ http://dl.acm.org/citation.cfm?id=980860>. Acesso em: jan. 2012.

BAUMAN, Z. Intimations of post modernity. Londres: Routledge, 1992.

O mal-estar da pós-modernidade. Rio de Janeiro: Zahar, 1998.

Modernidade e ambivalência. Rio de Janeiro: Zahar, 1999.

Comunidade. Rio de Janeiro: Zahar, 2003.

Vidas desperdiçadas. Rio de Janeiro: Zahar, 2005.

Los retos de la educación em la modernidad líquida. Barcelona: Gedisa, 2007.

2008.

Vida para consumo: a transformação das pessoas em mercadorias. Rio de Janeiro: Zahar Editora,

BEECH, J. A internacionalização das políticas educativas na América Latina. Currículo sem fronteiras, v. 9, n. 2, jul./dez. 2009. Disponível em: <www.curriculosemfronteiras.org> . Acesso em: 5 jan. 2012.

BERMAN, M. Tudo que é sólido desmancha no ar: Marx, modernismo e modernização. In: Aventuras no Marxismo. São Paulo: Companhia das Letras, 2001.

BERNARDO, F. C. Vida escolar - O mapa da crise na perspectiva discente. 2011. 138 f. Dissertação (Mestrado em Linguística) - Programa de Pós-graduação em Linguística, Universidade Federal de Juiz de Fora, Juiz de Fora, 2011.

BOSI, A. Céu e inferno - ensaios de crítica literária e ideológica. Local: Editora 34/Duas Cidades, 2003. $45 \mathrm{p}$.

BRASIL, M. M. S. A sala de aula de Língua Portuguesa: uma proposta comprometida com o protagonismo. 2015. 125 f. Dissertação (Mestrado Profissional em Letras) - Universidade Federal de Juiz de Fora, Juiz de Fora, 2015.

BYBEE, J. Language, usage and cognition. Cambridge: Cambridge University Press, 2010. 
CHAUÍ M. Neoliberalismo e Universidade. Conferência proferida na abertura do seminário "A construção democrática em questão". São Paulo, USP, 22 de abril de 1997. Disponível em: $<$ http://pt.scribd.com/doc/16627324/neoliberalismo-e-universidade-Marilena-Chaui>

A universidade operacional. Folha de S.Paulo, São Paulo, p. 3-9, maio 1999. Disponível em: <www.folha.uol.com.br> . Acesso em: 7 jan. 2012.

CROFT, W.; CRUSE, A. Cognitive Linguistics. Cambridge: Cambridge University Press, 2004.

CUNHA, L. A. O ensino superior no octênio FHC. Educação \& Sociedade, v. 24, n. 82, abr. 2003. out. 2004.

Desenvolvimento desigual e combinado no ensino superior. Educação \& Sociedade, v. 25, n. 80,

DELORY-MOMBERGER, C. A condição biográfica: ensaios sobre a narrativa de si na modernidade avançada. Tradução: Carlos Galvão Braga, Maria da Conceição Passegi, Nelson Patriota. Natal, RN: EDUFRN, 2012.

As histórias de vida: Da invenção de si ao projeto de formação. Tradução: Albino Pozzer. Natal:

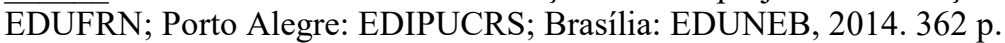

Biografia e educação: figuras do indivíduo-projeto. Tradução: Maria da Conceição Passegi, João Gomkes da Silva Neto, Luis Passeggi. Natal, RN: EDUFRN; São Paulo: Paulus, 2008.

FABRÍCIO, B.; BASTOS, L. Narrativas e identidade de grupo: a memória como garantia do "nós" perante o "outro". In: DIAS PEREIRA, M. das G.; PINHEIRO BASTOS, C. R.; PEREIRA, T. C. (Org.\}. Discursos socioculturais em interação. Interfaces entre a narrativa, a conversação e a argumentação: navegando nos contextos da escola, saúde, empresa, mídia, política e migração. Rio de Janeiro: Garamond, 2009.

FILLMORE, C. J. Semântica de frames. Cadernos de Tradução, Porto Alegre, n. 25, jul.-dez. 2009. Beyond The Core (BTC) Project. 2007.

. 'Corpus linguistics' or 'computer corpus linguistics'. In: J. SVARTVIK (Org.). Directions in

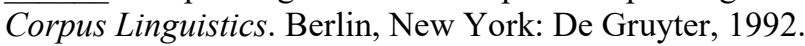
Grammatical Construction theory and the familiar dichotomies. In: DIETRICH, R.;

GRAUMANN, C. (Eds.) Language processing in social context. North-Holland: Elservier Science Publishers B.V, p. 17-38, 1989.

Frame and the semantics of understanding. Quarderni di Semantica, v. 6, n. 2, p. 222-253, 1985. Frame semantics. In: LINGUISTIC SOCIETY OF KOREA (Eds.). Linguistics in the Morning

Calm: Selected Papers from SICOL-1981. Seoul: Hanshin, 1982. p. 111-113.

Topics in lexical semantics. In: COLE. Currents Issues in Linguistic Theory. Indiana: Indiana University Press, 1979.

The case for case reopened. In: COLE, P.; SADDOCK, J. (Ed.) Grammatical Relation. New York: Academic Press, 1977.

FILLMORE, C. J.; JOHNSON, C. R.; PETRUCK, M. R. L. Background to FrameNet. International Journal of Lexicography, v. 16, n. 3, p. 235-250, 2003.

FILLMORE, C. J.; JOHNSON, C.R. The FrameNet tagset for frame-semantic and syntactic coding of predicate-argument structure. International Computer Science Institute, 2000. Disponível em: $<$ http://dl.acm.org/citation.cfm?id=974313>

FONSECA, C. A. Frames e discurso discente - desvelando indicadores de sucesso de um projeto escolar. 2015. 215 f. Dissertação (Mestrado em Lingüística) - Programa de Pós-graduação em Linguística, Universidade Federal de Juiz de Fora, Juiz de Fora, 2015.

FONTES, M. R. Equação entre educação da oralidade e educação de valores na pré-escola. Dissertação, 2012. 158 f. (Mestrado em Linguística) - Programa de Pós-graduação em Linguística, Universidade Federal de Juiz de Fora, Juiz de Fora, 2012.

FRIGOTTO, G.; CIAVATTA, M. Educação Básica no Brasil na década de 1990: subordinação ativa e consentida à lógica do mercado. Educação e Sociedade, Campinas, v. 24, n. 82, abr. 2003. Disponível em: <www.cedes.unicamp.br>. Acesso em: 3 jan. 2012.

GAWRON, J.M. Frame Semantics. Manuscript, San Diego State University, 2008.

GIDDENS, A. A transformação da intimidade: sexualidade, amor e erotismo nas sociedades modernas. São Paulo: UNESP, 1992. . As consequências da Modernidade. São Paulo: UNESP, 1991.

GOLDBERG, A. Constructions at work: thenature of generalization in language. Oxford: Oxford University Press, 2006.

MIRANDA, Neusa Salim; LOURES, Luciene Fernandes. Da análise semântica do discurso à ação educativa - um mapa da crise da sala de aula. Linguagem em (Dis)curso - LemD, Tubarão, SC, v. 16, n. 3, p. 525-546, set./dez. 2016. 
Constructions: a construction Grammar approach toargumentstructure. London: The University of Chicago Press, 1995.

ISHIKAWA, C. M. L. A ressignificação das práticas interacionais e linguísticas na sala de aula de Língua Portuguesa. 2016. 132 f. Dissertação (Mestrado Profissional em Letras) - Universidade Federal de Juiz de Fora, Juiz de Fora, 2015.

LA TAILLE,Y.; MENIN, M. S. de S. (Org.). Crise de valores ou valores em crise? Porto Alegre: Artmed, 2009.

LA TAILLE, Y. Formação ética: de tédio ao respeito de si. Porto Alegre: Artmed, 1999.

LIMA, F. R. O. Perspectiva discente sobre a formação profissional em Letras/UFJF: construindo um diálogo interteórico a partir da análise semântica do discurso. 2014. 241 f. Tese (Doutorado em Linguística) - Programa de Pós-graduação em Linguística, Universidade Federal de Juiz de Fora, Juiz de Fora, 2014.

A perspectiva discente do frame aula. 2009. 149 f. Dissertação (Mestrado em Linguística) Programa de Pós-graduação em Linguística, Universidade Federal de Juiz de Fora, Juiz de Fora, 2009. LOURES, L. F. A autoimagem do aluno de Português à luz da Semântica de Frames. 2013. 135 f. Dissertação (Mestrado em Linguística) - Programa de Pós-graduação em Linguística, Universidade Federal de Juiz de Fora, Juiz de Fora, 2013.

MACEDO, E. Formação de professores e diretrizes curriculares nacionais: para onde caminha a educação? Teias, Rio de Janeiro, 2000. Disponível em: <www.periodicos.proped.pro.br> Acesso em: fev. 2014.

MIRANDA, N. S. Projeto Práticas de Oralidade e Cidadania-3 - $3^{\mathrm{a}}$ etapa. EDITAL UNIVERSAL FAPEMIG /2011.

. Projeto Práticas de Oralidade e Cidadania-2 - 2a etapa. EDITAL UNIVERSAL -

FAPEMIG/2009.

Projeto Práticas de Oralidade e Cidadania-1 - $1^{\mathrm{a}}$ etapa. EDITAL UNIVERSAL -

FAPEMIG/2007.

Cala a boca não morreu. Revista da ANPOLL, v. 18, Campinas-SP, p.159-182, jan./jun. 2005.

MIRANDA, N. S.; BERNARDO, F. C. Frames, Discurso e Valores. Cadernos de Estudos Linguísticos, Campinas - SP, jan./jun. 2013.

MIRANDA, N. S.; SALOMÃO, M. M. M. (Org.). Construções do Português do Brasil: da gramática ao discurso. Belo Horizonte: UFMG, 2009. 389 p.

MIRANDA; SANTOS, T. M. B. (colaboradora); DEL-GAUDIO, S.M.A. (colaboradora). Reflexão metalinguística no ensino fundamental. Belo Horizonte: CEALE/FAE/UFMG -Coleção Alfabetização e Letramento, 2006. V. 1. 114 p.

MOITA LOPES, L. P. da. Práticas narrativas como espaço de construção das identidades sociais: uma abordagem socioconstrucionista. In. RIBEIRO, T. B.; LIMA, C. C.; LOPES, M. T. D. (Org.) Narrativa identidade e clínica. Rio de Janeiro: Edições IPUB/CUCA, 2001. p. 56-71.

MORIN, A. Pesquisa-ação integral e sistêmica: uma antropopedagogia renovada. Tradução Michel Thiollent. Rio de Janeiro: DP\&A, 2004.

NÓBREGA, A. N; MAGALHÃES, C. E. A. Narrativa e identidade: Contribuições da avaliação no processo de (re-)construção identitária em sala de aula universitária. Veredas, Juiz de Fora, v. 16, n. 2, p. 68-84, 2012.

PEREIRA, L. C. de S. Conceptualização e ação - um retrato discente da sala de aula. 2008.115 f. Dissertação (Mestrado em Lingüística) - Universidade Federal de Juiz de Fora, Coordenação de Aperfeiçoamento de Pessoal de Nível Superior, 2008.

PERINI, M. A. Sofrendo a gramática: ensaios sobre a linguagem. 3. ed. São Paulo: Ática, 2000.

PETRUCK, M. R. L. Frame Semantics. In: VERSCHUEREN, J. OSTMAN, J.; BLOMMAERT, J. (Eds.) Handbook of Pragmatics. Amsterdam/Philadelphia: John Benjamins, 1996.

PINHEIRO, R. M. M. O frame aula: uma análise sociocognitiva do discurso docente. $2009.149 \mathrm{f}$. Dissertação (Mestrado em Linguística) - Programa de Pós-graduação em Linguística, Universidade Federal de Juiz de Fora, Juiz de Fora, 2009.

REGO, T. C. Memórias de escola: Cultura escolar e constituição de singularidades. Petrópolis (RJ): Vozes, 2003.

MIRANDA, Neusa Salim; LOURES, Luciene Fernandes. Da análise semântica do discurso à ação educativa - um mapa da crise da sala de aula. Linguagem em (Dis)curso - LemD, Tubarão, SC, v. 16, n. 3, p. 525-546, set./dez. 2016. 
RUPPENHOFER, J.; ELLSWORTH, M.; PETRUCK, M. R. L.; JOHNSON, C. R.; SCHEFFCZYK, J. 2010. FrameNet II: Extended theory and practice. Disponível em: $<$ http://framenet.icsi.berkeley.edu/index.php?option=com_wrapper\&Itemid=126>. Acesso em: fev. 2012. SALOMÃO, M. M. M. FrameNet Brasil: um trabalho em progresso. Calidoscópio, São Leopoldo, v. 7, n. 3, set./dez. 2009.

A questão da construção do sentido e a revisão da agenda dos estudos da linguagem. Veredas, Juiz de Fora, v. 3, n.1, p. 61-79, jan./jun. 1999.

SIQUEIRA, A. C. T. A semântica de frames na análise do discurso discente - traçando o perfil do professor de português. 2013. 153 f. Dissertação (Mestrado em Linguística) - Programa de Pósgraduação em Linguística, Universidade Federal de Juiz de Fora, Juiz de Fora, 2013.

TEIXEIRA, A. P. A semântica de frames na análise do discurso docente - indicadores de sucesso das práticas de ensino de Língua Portuguesa. 2014. 161 f. Dissertação (Mestrado em Linguística) - Programa de Pós-graduação em Linguística, Universidade Federal de Juiz de Fora, Juiz de Fora, 2014.

THORNBORROW, J; COATES, J. The sociolinguistics of narrative. Amsterdam: John Benjamins, 2005. TOMASELLO. M. Origens culturais da aquisição do conhecimento humano. São Paulo: Martins Fontes, 2003.

The cultural origins of human cognition. Harvard University Press, 1999.

YIN, R. K. Estudos de caso: planejamento e métodos. Tradução de Daniel Grassi. 2. ed. Porto Alegre: Bookman, 2001.

Recebido em: 04/07/16. Aprovado em: 20/08/16.

Title: From the semantic discourse analysis to educational action - a classroom crisis map Authors: Neusa Salim Miranda; Luciene Fernandes Loures

Abstract: This article aims to present the path of hybrid nature macro project - both linguistic and educational - that, for a decade, before the development of twelve Case Studies in the elementary school scenario, works with a discourse analysis model based on Frame Semantics and on Usage-based model. From the narratives of practices of students and teachers as a constitutive methodology of your corpora, this study allowed us to draw the classroom crisis map, with your causes, consequences and also your escapes, which has led not just for a consolidation of a discourse model analysis, but a new way for an education action in the Portuguese classroom and in the processes of teacher's formation.

Keywords: Frame Semantics. Discourse analysis. School experience.

Título: Del análisis semántico des discurso hasta la acción educativa - un mapeo de la crisis de la sala de aula

Autores: Neusa Salim Miranda; Luciene Fernandes Loures

Resumen: Este artículo presenta una trayectoria de un macro-proyecto de naturaleza híbrida - Lingüistica y Educación - que por una década, delante el desarrollo de doce Estudios de Caso fijados en el escenario escolar, viene trabajando un modelo de análisis del discurso basado en la Semántica de Frames y en los Modelos de Lenguaje anclados en el Uso. Se valiendo de la narrativa de prácticas de alumnos y profesores como metodología de constitución de sus corpora, este estudio he permitido trazar un mapeo de la crisis de la sala de aula, con sus causas, consecuencias y también rutas de salida, lo que hay conducido no solo hasta la consolidación de un modelo de análisis del discurso, pero a nuevos caminos para la acción educativa en clases de Lengua Portuguesa y en el proceso de entrenamiento de profesores.

Palabras-clave: Semántica de Frames. Análisis del discurso. Experiencia escolar.

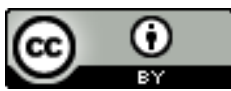

Este texto está licenciado com uma Licença Creative Commons Atribuição 4.0 Internacional.

MIRANDA, Neusa Salim; LOURES, Luciene Fernandes. Da análise semântica do discurso à ação educativa - um mapa da crise da sala de aula. Linguagem em (Dis)curso - LemD, Tubarão, SC, v. 16, n. 3, p. 525-546, set./dez. 2016. 